\title{
Effect of Seed Size on Germination and Seedlings Growth of Some forest Tree Species
}

\author{
M. K. Singh ${ }^{1 *}$, Fateh Singh ${ }^{1}$, Meharchand ${ }^{1}$ and Narender Kumar ${ }^{2}$ \\ ${ }^{1}$ CCS Haryana Agricultural University, Hisar, India \\ ${ }^{2}$ Krishi Vigyan Kendra, Kurukshetra and Bawal, India \\ *Corresponding author
}

\section{Keywords}

Tree species, Seed size, Seedling growth

\section{Article Info}

Accepted: 12 December 2020 Available Online: 10 January 2021
Pot experiment was conducted at Balsamand Research Farm in Department of Forestry, CCSHAU, Hisar. In this experiment mature seeds of Ailanthus excelsa, Acacia nilotica, Acacia tortilis, Dalbergia sissoo, Prosopis cineraria, Prosopis juliflora and Azadirachta indica were collected from middle age pluse trees from Balsamand Research Area and nearby places. The seeds of trees species were separated as large, medium and small on visual basis and measure its test weight, seed length, seed breadth and seed thickness with the help of vernier caliper and analysis its Test weight, germination percentage, initiation of germination, shoot length, root length, collar diameter, fresh and dry root and shoot weight of seedlings and found that large seeds of each tree species performed significantly better than medium and small seeds in terms of growth parameters of seedlings of tree species.

\section{Introduction}

Seed size may affect the fitness of parent plants and regeneration process (Silvertown, 1989). Larger seeds have greater abilities to survive in water stress condition (Venable and Brown, 1988). The seeds may differ in size, weight and density due to production environment and cultivation practices. The seeds size is an important component of seed quality which affects the crop growth performance (Adebisi et al., 2011). Many factors may affect the seed size and seedling fitness. The important effect of seed size on seedling quality, seedling size and adaptability
(Capinera 1979). Starch and other energy reserves of seed may depend on seed size which is an important factor for germination and initial growth of seedlings. Germination of seeds depends on the ability of seeds to use reserves material more efficiently. Higher seedling survival, growth and better field performance was observed in larger seeds than smaller seeds Ambika et al., 2014. Grading of seed on based of size is a common practice in a majority of plant species to regulate the seed germination and seedling growth. Large healthy seeds give healthy seedlings which is important criteria for transplant in the field reported by Singh and Saxena, 2009. 
Keeping in view the above facts the experiment was conducted to find out the best size of seeds of each tree species for obtaining the healthy seedlings for transplant in the field condition.

\section{Materials and Methods}

The pot experiment was conducted at Balsamand Research Farm of Forestry Department, CCSHAU, Hisar. Seeds of different tree species namely Ailanthus excelsa, Acacia nilotica, Acacia tortilis, Dalbergia sissoo, Prosopis cineraria, Prosopis juliflora and Azadirachta indica were collected from middle age pluse trees from Balsamand Research Area and nearby places, these seeds size were separated as large, medium and small size on visual basis and its length, breadth and thickness were measured with the help of vernier caliper as shown in Tabe-1.

25 Seeds of each tree species were selected on seed size basis and sown in pots filled with well rotten FYM and nursery soil in 1:1 ratio. After recorded the germination percentage, 4 plants in each pots were maintained. Test weights $(\mathrm{g})$, germination $(\%)$, initiation of germination (days), fresh and dry root and shoot weight $(\mathrm{g})$, root and shoot length $(\mathrm{cm})$ were analyzed.

\section{Statistical analysis}

The seedlings were maintained in pots in completely randomized design with three treatments: large, medium and small seeds.

Ten replications with three plants per replication were used for each treatment. Statistical procedures were carried out with the Software Package OP STAT developed by CCSHAU, Hisar. Significant differences were based on $\mathrm{P} \leq 0.05$.

\section{Results and Discussion}

In Table: 2. Maximum test weight was found in Azadirachta indica followed by Acacia nilotica, Prosopis cineraria where as minimum was recorded in Dalbergia sissoo. Test weight was recorded higher in larger seeds than medium and small seed size. Among the tree species test weight was found significantly higher in Azadirachta indica followed by Acacia nilotica, Prosopis cineraria whereas, significantly lower test weight was recorded in Dalbergia sissoo. The size of the seeds is important factor in the germination and early stage of seedlings growth reported by Girish et al., 2001. Wood et al, 1977 also reported that different size of seeds having different levels of food storage may be important factor which influences the germination and growth of the seedlings. Sundriyal, 2017 observed that seed weight were significantly affected the seedlings growth of some tropical rainforest tree species.

Germination percent was found significantly higher in Prosopis juliflora seeds followed by Ailanthus excelsa, Azadirachta indica and Acacia nilotica compared to Dalbergia sissoo. Among the seeds size larger seeds performed better than medium and small seed size of each tree species under studied. Ahirwar, 2012 observed that germination percentage significantly declined with reduction in size and weight of the seeds. Chancon et al., 1998 reported that larger seeds of Cryptocarya alba germinate in more number than small seeds. Larger seeds have positive effect on germination observed by Vera, 1997. Mtambalika et al, 2014 also reported that larger seeds had the highest germination percentage than small seeds. Attri et al., 2018 also reported that large seeds size gave maximum germination and to produce more vigorous seedlings than small seeds. 
Table.1 Morphological characters of seeds of different tree species

\begin{tabular}{|c|c|c|c|c|c|c|c|c|c|c|c|c|}
\hline \multirow[t]{2}{*}{$\begin{array}{l}\text { Treatments/Tree } \\
\text { species }\end{array}$} & \multicolumn{3}{|c|}{ Test weight (g) } & \multicolumn{3}{|c|}{ Seed length (mm) } & \multicolumn{3}{|c|}{$\begin{array}{c}\text { Seed breadth } \\
(\mathbf{m m})\end{array}$} & \multicolumn{3}{|c|}{$\begin{array}{c}\text { Seed thickness } \\
(\mathbf{m m})\end{array}$} \\
\hline & $\mathbf{L}$ & M & $\mathbf{S}$ & $\mathbf{L}$ & $\mathbf{M}$ & $\mathbf{S}$ & $\mathbf{L}$ & $\mathbf{M}$ & $\mathbf{S}$ & $\mathbf{L}$ & M & $\mathbf{S}$ \\
\hline Ailanthus excelsa & 5.37 & 4.81 & 3.26 & 10.57 & 8.77 & 7.73 & 6.07 & 5.37 & 4.86 & 2.78 & 2.30 & 2.04 \\
\hline Acacia nilotica & 7.30 & 6.10 & 4.80 & 9.48 & 7.20 & 6.30 & 6.97 & 5.57 & 5.26 & 3.28 & 2.58 & 2.46 \\
\hline Acacia tortilis & 3.53 & 2.82 & 2.08 & 6.21 & 5.62 & 5.25 & 5.15 & 4.38 & 3.62 & 2.98 & 2.34 & 2.16 \\
\hline Dalbergia sissoo & 1.13 & 0.88 & 0.62 & 9.49 & 7.53 & 5.98 & 4.69 & 3.81 & 2.80 & 0.64 & 0.59 & 0.36 \\
\hline Prosopis cineraria & 6.05 & 5.03 & 3.37 & 7.45 & 6.39 & 5.93 & 5.57 & 4.67 & 3.87 & 2.38 & 2.10 & 2.06 \\
\hline Prosopis juliflora & 3.82 & 2.62 & 2.01 & 6.48 & 5.26 & 4.96 & 3.95 & 3.42 & 3.17 & 2.25 & 1.72 & 1.09 \\
\hline Azadirachta indica & 26.21 & 20.72 & 15.11 & 15.40 & 12.76 & 9.44 & - & - & - & 9.01 & 6.97 & 5.79 \\
\hline
\end{tabular}

Table.2 Effect of seed size on seed germination of different tree species

\begin{tabular}{|l|c|c|c|c|c|c|c|c|c|}
\hline \multirow{2}{*}{ Treatments/Tree species } & \multicolumn{3}{|c|}{ Test weight $(\mathbf{g})$} & \multicolumn{3}{c|}{ Germination (\%) } & \multicolumn{3}{c|}{$\begin{array}{c}\text { Initiation of } \\
\text { germination (days) }\end{array}$} \\
\cline { 2 - 12 } & L & M & S & L & M & S & L & M & S \\
\hline Ailanthus excelsa & 5.37 & 4.81 & 3.26 & 88.0 & 72.0 & 32.0 & 4 & 4 & 6 \\
\hline Acacia nilotica & 7.30 & 6.10 & 4.80 & 82.0 & 64.0 & 41.0 & 5 & 6 & 9 \\
\hline Acacia tortilis & 3.53 & 2.82 & 2.08 & 78.0 & 52.0 & 32.0 & 5 & 6 & 9 \\
\hline Dalbergia sissoo & 1.13 & 0.88 & 0.62 & 72.0 & 43.0 & 31.0 & 3 & 3 & 6 \\
\hline Prosopis cineraria & 6.05 & 5.03 & 3.37 & 76.0 & 52.0 & 33.0 & 7 & 7 & 9 \\
\hline Prosopis juliflora & 3.82 & 2.62 & 2.01 & 91.0 & 76.0 & 46.0 & 7 & 8 & 10 \\
\hline Azadirachta indica & 26.21 & 20.72 & 15.11 & 86.0 & 65.0 & 36.0 & 3 & 3 & 6 \\
\hline Mean & $\mathbf{7 . 6 3}$ & $\mathbf{6 . 1 4}$ & $\mathbf{4 . 4 6}$ & $\mathbf{8 1 . 7}$ & $\mathbf{6 0 . 6}$ & $\mathbf{3 5 . 4}$ & $\mathbf{4 . 9}$ & $\mathbf{5 . 3}$ & $\mathbf{7 . 9}$ \\
\hline CD at 0.05 & $\mathbf{0 . 2 3}$ & $\mathbf{0 . 1 9}$ & $\mathbf{0 . 2 8}$ & $\mathbf{1 . 7 7}$ & $\mathbf{1 . 7 6}$ & $\mathbf{1 . 7 2}$ & $\mathbf{1 . 6 8}$ & $\mathbf{2 . 1 1}$ & $\mathbf{2 . 0 0}$ \\
\hline
\end{tabular}

Table.3 Effect of seed size on seedling growth of different tree species

\begin{tabular}{|c|c|c|c|c|c|c|c|c|c|}
\hline \multirow{2}{*}{$\begin{array}{l}\text { Treatments/Tree } \\
\text { species }\end{array}$} & \multicolumn{3}{|c|}{ Shoot length (cm) } & \multicolumn{3}{|c|}{ Root length (cm) } & \multicolumn{3}{|c|}{ Collar diameter (mm) } \\
\hline & $\mathbf{L}$ & M & $\mathbf{S}$ & $\mathbf{L}$ & $\mathbf{M}$ & $\mathbf{S}$ & $\mathbf{L}$ & $\mathbf{M}$ & $\mathbf{S}$ \\
\hline Ailanthus excelsa & 18.2 & 14.4 & 6.9 & 25.6 & 16.8 & 11.6 & 5.02 & 3.17 & 2.50 \\
\hline Acacia nilotica & 21.6 & 15.2 & 8.2 & 41.6 & 26.1 & 19.7 & 1.65 & 1.48 & 1.03 \\
\hline Acacia tortilis & 23.6 & 17.2 & 11.6 & 41.2 & 34.7 & 23.6 & 3.22 & 2.21 & 0.98 \\
\hline Dalbergia sissoo & 17.6 & 13.3 & 7.3 & 36.1 & 28.4 & 12.2 & 1.96 & 1.26 & 0.96 \\
\hline Prosopis cineraria & 14.9 & 11.5 & 8.3 & 60.2 & 48.2 & 25.6 & 2.30 & 1.79 & 1.23 \\
\hline Prosopis juliflora & 31.6 & 19.7 & 12.7 & 47.6 & 36.4 & 27.3 & 2.07 & 1.62 & 1.06 \\
\hline Azadirachta indica & 14.1 & 11.0 & 7.8 & 22.5 & 17.2 & 14.2 & 3.81 & 1.81 & 1.36 \\
\hline Mean & 20.2 & 14.6 & 9.0 & 39.3 & 29.7 & 19.2 & 2.86 & 1.90 & 1.30 \\
\hline CD at 0.05 & 1.41 & 1.12 & 0.39 & 1.16 & 0.68 & 0.80 & 0.18 & 0.15 & 0.27 \\
\hline
\end{tabular}


Table.4 Effect of seed size on fresh and dry weight of seedlings of different tree species

\begin{tabular}{|l|c|c|c|c|c|c|c|c|c|c|c|c|}
\hline \multirow{2}{*}{$\begin{array}{l}\text { Treatments/Tree } \\
\text { species }\end{array}$} & \multicolumn{4}{|c|}{ Fresh weight (g) } & \multicolumn{4}{c|}{ Dry weight (g) } \\
\cline { 2 - 15 } & \multicolumn{3}{|c|}{ Shoot } & \multicolumn{3}{|c|}{ Root } & \multicolumn{3}{c|}{ Shoot } & \multicolumn{3}{c|}{ Root } \\
\hline A & M & S & L & M & S & L & M & S & L & M & S \\
\hline Acacia nilotica & 2.90 & 1.80 & 0.79 & 1.20 & 0.90 & 0.31 & 1.05 & 0.65 & 0.28 & 0.34 & 0.26 & 0.11 \\
\hline Acacia tortilis & 2.16 & 1.28 & 0.83 & 1.60 & 0.35 & 0.16 & 0.78 & 0.46 & 0.28 & 0.51 & 0.11 & 0.06 \\
\hline Dalbergia sissoo & 3.70 & 2.80 & 1.01 & 2.40 & 1.60 & 0.21 & 1.34 & 1.02 & 0.35 & 0.77 & 0.51 & 0.07 \\
\hline Prosopis cineraria & 2.01 & 0.82 & 0.35 & 0.89 & 0.71 & 0.14 & 0.71 & 0.37 & 0.08 & 0.26 & 0.20 & 0.03 \\
\hline Prosopis juliflora & 0.94 & 0.63 & 0.33 & 1.25 & 0.71 & 0.56 & 0.40 & 0.15 & 0.08 & 0.60 & 0.36 & 0.22 \\
\hline Azadirachta indica & 2.69 & 0.98 & 0.51 & 2.12 & 0.77 & 0.26 & 1.00 & 0.26 & 0.17 & 0.67 & 0.24 & 0.09 \\
\hline Mean & 3.10 & 2.60 & 1.50 & 1.40 & 0.80 & 0.42 & 1.40 & 1.23 & 0.51 & 0.44 & 0.13 & 0.01 \\
\hline CD at $\mathbf{0 . 0 5}$ & $\mathbf{2 . 5 0}$ & $\mathbf{1 . 5 6}$ & $\mathbf{0 . 7 6}$ & $\mathbf{1 . 5 5}$ & $\mathbf{0 . 7 8}$ & $\mathbf{0 . 3 5}$ & $\mathbf{0 . 9 5}$ & $\mathbf{0 . 5 9}$ & $\mathbf{0 . 2 5}$ & $\mathbf{0 . 5 1}$ & $\mathbf{0 . 2 7}$ & $\mathbf{0 . 0 8}$ \\
\hline & $\mathbf{0 . 1 9}$ & $\mathbf{0 . 1 6}$ & $\mathbf{0 . 1 9}$ & $\mathbf{0 . 3 5}$ & $\mathbf{0 . 1 1}$ & $\mathbf{0 . 0 9}$ & $\mathbf{0 . 2 1}$ & $\mathbf{0 . 0 6}$ & $\mathbf{0 . 0 5}$ & $\mathbf{0 . 2 4}$ & $\mathbf{0 . 0 6}$ & $\mathbf{0 . 0 3}$ \\
\hline
\end{tabular}

In case of initiation of germination, seeds of Dalbergia sissoo followed by Azadirachta indica germinate within 3 days after sowing. Whereas, germination was delayed in Prosopis juliflora followed by Prosopis cineraria in large seed size treatment (L). Small seeds (S) of each tree species took more time to germinate after sowing. It is also noted that larger seeds germinate better and earlier than small seeds. Uniyal et al., 2007 reported that larger seeds of Azadirachta indica germinated earlier compared to small seeds. Cicek and Tilki, 2007 reported that large seeds germinate early and showed better germination than small seeds. Mao et. al., 2019 reported that large and medium seeds of Pinus thunbergii had a higher germination rate, germination index, vigor index than small seeds.

In Table: 3. In different seeds size of trees species, shoot length, root length and collar diameter was observed maximum in larger seeds than medium seeds and minimum was recorded in small seeds of each tree species similar observation also observed by Uniyal et al., 2007 that longer shoot and root length were observed in A. indica from larger size seeds. Shoot length was found significantly higher in Prosopis juliflora followed by Acacia nilotica than Azadirachta indica and
Prosopis cineraria. Larger seeds have greater shoot growth rate reported by Bonfil, 1998. In case of root length, the root of Prosopis cineraria was found significantly larger than other tree species roots. Collar diameter was recorded significantly higher in Ailanthus excelsa and Acacia nilotica followed by Dalbergia sissoo. Mtambalika et al., 2014 also reported that significant difference in seedling height and root collar diameter among the different seed sizes with large seeds having the higher seedling height. Seed size significantly affected the seedlings emergence, seedling survival recorded by Cicek and Tilki, 2007. Large seeds of Saraca asoca attended higher collar diameter as compared to smaller seeds reported by Mirgal et al., 2016

In table 4. Fresh shoot weight was recorded significantly higher in Acacia nilotica followed by Azadirachta indica as compared with Prosopis cineraria. In case of Fresh root weight, it was found significantly higher in Acacia tortilis followed by Prosopis juliflora and minimum was recorded in Dalbergia sissoo. He et al., 2007 reported that seedlings from large seeds of Ligularia virgaurea has significant higher rates of biomass accumulation than did seedlings from small seeds. 
In Acacia tortilis, dry shoot weight was recorded significantly higher followed by Azadirachta indica when compared with Prosopis cineraria followed Dalbergia sissoo. Dry root weight of Acacia tortilis was recorded significantly higher followed by Prosopis juliflora as compared with other tree species under studied. Large seeds affect significantly on seedlings dry weight observed by Cicek and Tilki, 2007. Total dry weight of seedlings of G.arborea raised from large size seeds was 2-3 times more than those from small size seeds. Seeds weight was strongly correlated with increase in seed size for $O$. paniculata and $D$. macrocarpus reported by Agboda, 1996. Mirgal et al., 2016 reported that larger seeds of Saraca asoca attended higher dry biomass and entire seedling biomass as compared to smaller seeds. Seedlings raised from medium seeds were at par with larger seeds in most of the traits.

It may be concluded that large seeds of each tree species have more advantages than medium and small seeds in terms of all the growth parameters like test weight, seed length, seed breadth and seed thickness, germination percentage, initiation of germination, completion of germination, shoot length, root length, collar diameter, fresh and dry root and shoot weight of seedlings under studied. It is recommendation that large and medium seeds size of each tree species are used for the production of good quality of seedlings for transplantation in the field.

\section{Acknowledgements}

The authors are thankful to Dr. Karan Ahlawat (Assistant Scientist), Department of forestry, CCSHAU, Hisar for providing valuable guidance and suggestions during experimentation.

\section{References}

Adebisi, M.A., Kehinde, T.O., Ajala, M.O., Olowu, E.F and Rasaki, S. 2011. Assessment of seed quality and potential longevity in elite tropical soybean (Glycine max L.) Merrill grown in Southwestern Nigeria. Niger. Agric. J. 42:94-103.

Agboda, D.A. 1996. The effect of seed size on germination and seedling growth of three tropical tree species. Journal of Tropical Forest Science. 9(1): 44-51.

Ahirwar, T.R. 2012. Effect of seed size and weight on seed germination of Alangium lamarchkii, Akola, India. Research Journal of Recent Sciences.1: 320-322.

Ambika, S., Manonmani, V., Somasundaram, G. 2014. Review on effect of seed size on seedling vigour and seed yield. Research Journal of Seed Science.7: 31-38.

Attri, A., Pant, K.S and Tiwari, P. 2018. Effect of seed size and pre-sowing treatment on germination of some important trees-A review. Research Journal of Chemical and Environmental Scineces. 6(1):104-113.

Bonfil, C. 1998. The effects of seed size, cotyledon reserves and herbivory on seedling survival and growth in Quercus rugosa and $Q$. laurina (Fagaceae). American Journal of Botany. 85:79-87.

Capinera, J. 1979. Qualitative variation in plants and insects: effect of propagule size on ecological plasticity. American Naturalist. 114: 350 - 361.

Chancon, P., Bustamante, R and Henriquez, C. 1998. The effect of seed size on germination and seedling growth of Cryptocarya alba (Lauraceae) in Chile. Revista Chilena de Historia National.71: 189-197.

Cicek, E and Tilki, F. 2007. Seed size effects 
on germination, survival and seedling growth of Castanea sativa Mill. Journal of Biological Sciences. 7: 438-441.

Girish B., Shahapurmath G.R., Kumar A.K.K. and Ganiger B.S 2001.Effect of seed size and depth of sowing on seed germination in Sapindus trifoliatus. My Forest. 37: 483-489.

He,Y.,Wang, M.,Wen,S.,Zhang, Y., Ma, T and Du, G. 2007. Seed size effect on seedling growth under different light conditions in the clonal herb Ligularia virgaurea in Qinghai Tibet Plateau. Acta Ecologica Sinica. 27(8): 30913108.

Mao, P.,Guo,L., Qi, L and Cao, B (2019). Effect of seed size and sand burial on germination and early growth of seedlings for coastal Pinus thunbergii Parl. In the Northern Shandong Peninsulo, China. Forests. 10:2-14.

Mirgal, A.B., Gunago, R.P and Salunkhe, C.B (2016). Seed size and its influence on germination, seedling growth and biomass in Saraca asoca Roxb. De Wilde, Critically endangered tree species of Western ghats, India. Journal of Applied and Natural Science. 8 (3): 1599-1602.

Mtambalika, K., Monthali, C., Gondwe, D and Missanjo, E (2014). Effect of seed size of Afzelia quanzensis on germination and seedling growth. International Journal of Forestry
Research. Article ID:384565.

Silvertown, J.W (1989). The paradox of seed size and adaptation. Trends in Ecology and Evolution.4:24-26.

Singh. N and Saxena A.K (2009). Seed size variation and its effect on germination and seedling growth of Jatropha curcas L. Indian Forester. 135 (8): 1135-1142.

Sundriyal, R.C (2017). Effect of seed size on germinatioin and seedling fitness in four tropical rain forest tree species. Indian Journal of Forestry. 40 (4): 313-322.

Uniyal, A.K., Singh, B and Todaria, N.P (2007). Effects of seed size, sowing orientation and depth on germination and seedling growth in Neem, Azadirachta indica. Seed Technology. 29: 68-75.

Venable, D.L and Brown, J.S (1988). The selective interactions of dispersal, dormancy and seed size as adaptations for reducing risk in variable environments. American Naturalist.130:370-398.

Vera, H.L (1997). Effects of altitude and seed size on germination and seedling survival of heathland plants in north Spain. Plant Ecology.133:101-106.

Wood D.W., Longden P.C. and Scott R.K (1977). Seed size variation, its extent, source and significance in field crops, Seed Sci. Technol. 2: 337-352.

\section{How to cite this article:}

Singh, M. K., Fateh Singh, Meharchand and Narender Kumar. 2021. Effect of Seed Size on Germination and Seedlings Growth of Some forest Tree Species. Int.J.Curr.Microbiol.App.Sci. 10(01): 2184-2189. doi: https://doi.org/10.20546/ijcmas.2021.1001.250 